Revista Española de Antropología Americana

ISSN: 0556-6533

https://dx.doi.org/10.5209/reaa.75272

\title{
En el interior de una alter-antropología. El perspectivismo amerindio en perspectiva
}

\author{
Antonela dos Santos ${ }^{1}$ y Florencia Tola ${ }^{2}$
}

Recibido: 31 de marzo de 2021 / Aceptado: 1 de julio de 2021

Resumen. Este artículo traza un recorrido por los sentidos que asumió el perspectivismo en la obra del antropólogo Eduardo Viveiros de Castro, uno de sus principales referentes desde 1990. Primero, abordaremos las nociones de persona, humano y sociedad tal como son desarrolladas en sus escritos iniciales sobre los araweté. Mostraremos cómo dicha etnografía le permitió elaborar temas centrales del perspectivismo amerindio en tanto teoría antropológica. Luego nos adentramos en una segunda etapa de su obra, en la cual el perspectivismo es conceptualizado como una metafísica chamánica amazónica y como una alter-antropología nativa con la cual dialogar y desde la cual repensar el naturalismo occidental. Buscamos enfatizar que el perspectivismo no surgió bajo la forma de una teoría metafísica, ya que la etnografía amazónica fue clave en su inspiración; y que tampoco emergió únicamente de la imaginación conceptual de este autor, puesto que dichas postulaciones se insertan en una historia disciplinar comenzada por el precursor del americanismo, Claude Lévi-Strauss. Concluimos poniendo en perspectiva su obra en la antropología contemporánea.

Palabras clave: Perspectivismo; metafísica; ontología; alter-antropología; Amazonía; antropología contemporánea.

\section{[en] Inside an Alter-Anthropology. Amerindian Perspectivism under Perspective}

\begin{abstract}
This article discusses the different senses of perspectivism along Viveiros de Castro's work, considering that since 1990s this anthropologist is one of its main referents. First, we focus on notions such as person, human and society as developed in his initial writings. We show how his ethnography among the Arawete enabled him to elaborate central themes in Amerindian perspectivism and postulate it as an anthropological theory. Then, we will discuss how in his later works perspectivism is conceptualized as a shamanistic metaphysic and a native alter-anthropology that enables us to rethink Western naturalism. We seek to emphasize that perspectivism did not emerge merely as a metaphysical theory, since Amazonian ethnography was key in its inspiration; nor did it comes solely from the conceptual imagination of Viveiros de Castro, since these postulations are part of a disciplinary history that begun with the precursor of Americanism, Claude Lévi-Strauss. Finally, we will conclude by putting under perspective Viveiros de Castro's work on Amerindian perspectivism and his contributions to contemporary anthropology.
\end{abstract}

Keywords: Perspectivism; Metaphysics; Ontology; Alter-anthropology; Amazonia; contemporary anthropology.

Becaria post-doctoral CONICET (Argentina). antodos@gmail.com

2 Investigadora Independiente CONICET (Argentina), Investigadora asociada al Centro EREA del LESC (UPO/

CNRS, Francia). tolatoba2015@gmail.com 
Sumario. 1. Introducción. 2. De humanos, enemigos y divinidades al perspectivismo como teoría antropológica. 3. Del perspectivismo como teoría antropológica al perspectivismo como metafísica amazónica y alter-antropología nativa. 4. De equívocos y antropologías en diálogo. 5. Pensando desde una alter-antropología.

Cómo citar: dos Santos, Antonela y Florencia Tola. 2022. "En el interior de una alter-antropología. El perspectivismo amerindio en perspectiva". Revista Española de Antropología Americana 52 (1): 127-141.

\section{Introducción}

Desde sus primeras formulaciones a mediados de los años 1990, el perspectivismo amerindio en tanto teoría antropológica que da cuenta de las particularidades sociocosmológicas de buena parte de los pueblos indígenas amazónicos, ha producido intensos debates no sólo dentro de la antropología, sino también de otras ciencias afines. En términos del brasileño Eduardo Viveiros de Castro (1996: 115), esta teoría supone que, dado que los distintos seres que componen el mundo amazónico están dotados de una apariencia corporal variable y específica a cada especie, también varía y es específica la manera en que unos y otros se ven a sí mismos y a los demás.

En las últimas décadas, el perspectivismo no sólo ha sido releído y modificado, sino también fuertemente criticado. Magnus Course (2013) señala que algunos investigadores de las Tierras Bajas Sudamericanas cuestionan el perspectivismo puntualizando en la falta de refinamiento de sus postulados o en su inadecuación a ciertos casos etnográficos y que "muchos de estos debates se ubican en el espacio entre el perspectivismo como fenómeno etnográfico y el perspectivismo como paradigma analítico, siendo este último una abstracción del primero" (Course 2013: 310)3.

El recorrido que proponemos en este artículo pretende, justamente, habitar ese espacio intermedio mostrando cómo etnografía y teoría fueron combinándose en la labor intelectual emprendida por Viveiros de Castro en los últimos treinta años. Para eso, recuperamos primero los escritos de carácter más etnográfico de este autor. Vemos allí que las teorizaciones araweté sobre la persona, lo humano y lo social, entre otros, fueron delineando una agenda de investigación que buscaba asir la sociocosmología de este pueblo sin recurrir a modelos teóricos construidos para otras áreas (cf. el texto seminal de Seeger et al. 1979). En un segundo momento, seguimos al antropólogo brasileño en su apuesta a pensar el perspectivismo como una metafísica chamánica amazónica y una alter-antropología nativa que nos enfrenta a modos de existencia que conceptualizan lo humano y lo extra-humano, lo social y lo individual, lo natural y lo cultural, de manera radicalmente diferente a como nosotros occidentales lo hacemos. Argumentaremos que, si el perspectivismo es una "bomba" (Latour 2009) capaz de hacer estallar nuestras descripciones, categorizaciones y teorizaciones antropológicas, lo es, entre otras cosas, debido a que alienta la confrontación entre antropologías, comparando y simetrizando diferentes modelos de autoridad intelectual.

En efecto, el potencial transformacional y la multiplicidad de visiones igualmente válidas y verdaderas -todos ellos, como veremos, rasgos del perspectivismo amerin-

Todas las citas bibliográficas en otros idiomas han sido traducidas por las autoras. 
dio- pueden estar al servicio de un proyecto que trasciende a Viveiros de Castro como intelectual, viaja más allá de la Amazonía y supera incluso los difusos límites de la Antropología como disciplina científica. Así, por ejemplo, el perspectivismo entre los yudjá muestra una recusa a la unilateralidad del conocimiento y a la operatividad de una "lógica jerárquica entre las partes y los todos" (Lima 2005: 213) que bien puede ser útil para pensar en otro tipo de relaciones epistemológicas entre la antropología indígena y la antropología sobre los indígenas. Si lo único que existe son verdades parciales dependientes de la perspectiva de cada sujeto, entonces no hay necesariamente preponderancia de un discurso sobre otro. Simetrizadas, las teorías y las acciones del otro, pueden modificar tanto el repertorio conceptual del antropólogo (y, por ende, su modo de producir antropología) como, en términos más amplios, su modo occidental de existir (Viveiros de Castro et al. 2019: 135).

La ausencia de una perspectiva englobante y trascendente condujo a Tânia Stolze Lima - estudiante y colega de Viveiros de Castro, y una de sus mayores interlocutoras en los comienzos de la teoría perspectivista- a sostener que el perspectivismo es un pensamiento "contra el Estado (P. Clastres, 1974), contra la forma Estado del pensamiento (Deleuze \& Guattari, 1980)" (2005: 213). Así como para los yudjá todo acontecimiento contiene el punto de vista propio y el del otro (Lima 1996: 37), sería posible también pensar una antropología contra las formas-Estado del pensamiento, donde la coexistencia de los discursos de antropólogos y nativos no dependiera ya ni de la tolerancia a lo diferente ni de la conversión de unos en otros, sino de un encuentro fructífero que actualice las virtualidades presentes en los distintos puntos de vista. El "arte de las distancias" (Viveiros de Castro 2009: 6) apunta, justamente, en esa dirección: ni asimilar el discurso nativo ni reducir su diferencia. Un movimiento similar sugerimos nosotras en este texto: tomar el discurso antropológico de Viveiros de Castro estableciendo con él una relación que mantenga esa justa distancia que ni reduce ni desconoce la potencia teórica y metodológica del perspectivismo, ni lo adopta acríticamente repitiéndolo y constatando que es posible su aplicación a otros casos etnográficos. Por el contrario, se trata de multiplicar sus alcances, explorando sus potencialidades y límites.

\section{De humanos, enemigos y divinidades al perspectivismo como teoría antropológica}

Las reflexiones de Viveiros de Castro sobre la noción de persona y de humano entre los araweté, desarrolladas en From the enemy's point of view: Humanity and divinity in an Amazonian society (1992), traslucen rasgos que serán centrales en su formulación posterior del perspectivismo. Su investigación con este pueblo tupí-guaraní del Xingú medio (Brasil) contempló tanto prácticas cotidianas y hechos de la organización social y de la vida ritual como discursos cosmológicos, escatológicos y relativos a las divinidades. A partir de ello teorizó sobre aspectos centrales de las sociocosmologías amazónicas tales como las generalizadas y potenciales transformaciones y la necesidad de la perspectiva y la exterioridad en la constitución de la persona y la sociedad. Esta agenda de trabajo, centrada en la cosmología y la mitología indígena, ha sido leída por antropólogos como Alcida Ramos (2012) como perniciosa para los mismos indígenas. La utilización de un "vocabulario exotizante" (Ramos 2012: 484-486) ligado a mitos y ritos que, en el sentido común, se asocian con la falsedad, el engaño y la mentira, conduciría, según esta autora, a ensanchar la brecha entre la 
"ciencia" occidental y el "pensamiento" indígena. Como resultado, se estaría socavando las demandas indígenas concretas al relegar las narrativas de estos pueblos a meras elucubraciones de poco valor.

La "metamorfosis interespecífica" (Viveiros de Castro 2015: 2294) entre humanos, enemigos y divinidades ${ }^{5}$ - posiciones centrales en la vida social araweté- da lugar, tal como Viveiros de Castro (1992) demuestra, a una sociocosmología no esencialista $^{6}$ en la que tanto bïde (humano) como awï (enemigo) no refieren a "esencias sustantivas" sino a una "posición o cualidad" (1992: 65). En estas cosmologías, la persona se halla en permanente transición y puede constantemente devenir-otro: para los araweté el ser humano se ubica entre el cielo y la tierra, el pasado y el futuro, y entre los muertos, los enemigos y los dioses ${ }^{7}$. En efecto, el muerto es el enemigo, el enemigo es un dios, el dios es el muerto y el muerto es uno (Viveiros de Castro 1992). Tal como vemos, la alteridad es intrínseca a la persona araweté (Viveiros de Castro 1992: 254) puesto que, más que un espejo, el otro es su destino: antes de la separación que dio lugar al cielo y la tierra, la muerte y la diferencia, los humanos eran dioses y, al morir, volverán a serlo (1992: 254-255). Los humanos araweté son mortales porque existen los dioses inmortales que los definen en contraposición ${ }^{8}$.

Aunque en su etnografía ya está el germen de lo que será luego el perspectivismo, recién con posterioridad Viveiros de Castro lo definirá propiamente como una "teoría indígena" (2015: 197)9 . Para eso retomó los conceptos de "cualidad perspectiva" (Århem 1993) y "relatividad perspectiva" (Gray 1996) y sostuvo que, según esta "concepción" (Viveiros de Castro 1996: 115), la manera en que los humanos perci-

4 Aunque publicados en el año 2015, los datos referidos corresponden a conferencias que Viveiros de Castro dictó en Cambridge en 1998. Allí, el autor recuperó la información etnográfica analizada en su tesis doctoral (1986) que dio lugar al libro del año 1992.

5 Nótese que en su publicación del año 1992, la alternancia de puntos de vista ocurre dentro de "dinámicas intrahumanas" (Viveiros de Castro 2015: 203, nota 8). Será con posterioridad que, influido por, entre otros, sus diálogos con Lima (1995), Viveiros de Castro extenderá sus postulaciones sobre el perspectivismo araweté a otras regiones de la Amazonía (y más allá de ella) y a fenómenos inter-especie.

6 Por los mismos años, también otros evidenciaron rasgos no-esencialistas en diversas sociocosmologías amazónicas. Ejemplo de ello es la investigación de Aparecida Vilaça (1992) sobre el canibalismo de los wari de Rondonia. Al respecto, Viveiros de Castro (en Vilaça 1992: XIV) sostiene que lo que los wari comen del otro no es su sustancia, sino su condición misma de enemigo. Predador y presa no remiten aquí a categorías estables sino que constituyen polos de una relación social recíproca y reversible que va cambiando de acuerdo al juego de perspectivas. Puede nombrarse también la investigación ya referida de Lima (1996) sobre los yudjá, para quienes el mundo sólo existe para el sujeto que lo percibe. Dice la autora: "Diríamos que aquello que los humanos aprehenden como caza, los puercos lo aprehenden como guerra. Pero esta es una formulación equivocada, porque supone un mismo y único acontecimiento (...). La caza de los puercos no pone en escena una misma realidad vista por dos sujetos, tal como sería el caso de nuestro modelo relativista. Por el contrario, ella pone en escena un acontecimiento para los humanos y un acontecimiento para los puercos. En otras palabras, ella se desdobla en dos acontecimientos paralelos (...) que son también correlativos y que no remiten a ninguna realidad objetiva o externa, equiparable a lo que entendemos por naturaleza" (Lima 1996: 34).

7 Esta idea de transformación permanente es descripta por Viveiros de Castro $(1986,1992)$ también en relación a los diversos elementos del cosmos y del cuerpo. Por ejemplo, se nos dice que el trueno y el arcoíris son índices de la transformación del muerto que va al cielo, que la cerveza fermentada es concebida como semen femenino y que la leche es cerveza para el bebé.

8 Entre los yudjá, en cambio, la relación preponderante es con el animal y, a diferencia de lo que sucede entre los araweté, hay allí una asimetría: mientras que el humano sabe que es visto por los animales como una persona con la cual relacionarse, el animal no sabe que los humanos lo ven a él como animal puesto que, "la condición de animal no puede ser concebida en primera persona; ella es una forma de conciencia de otro" (Lima 1996: 29).

9 Véase, en especial, Viveiros de Castro 1996, 1998. 
ben a los animales y a otras subjetividades (dioses, espíritus, muertos, etc.) difiere de la forma en que dichos seres perciben a los humanos y a sí mismos. En "condiciones normales", los humanos se ven como humanos, ven a los animales como animales y a los espíritus como espíritus; los predadores y los espíritus ven a los humanos como presas; y las presas ven a los humanos como espíritus o predadores. En cambio, "en sus propias casas" (Viveiros de Castro 2015: 202), los animales y los espíritus se perciben como humanos, es decir, son antropomorfos ${ }^{10}$, tienen cultura y un sistema social propio. Estas diferencias que se expresan en términos visuales son, en verdad, diferencias relacionales: que una entidad vea a otra de una manera determinada responde menos al equipamiento visual que ella posee que al tipo de relaciones que entabla con esas otras entidades. El perspectivismo amazónico usa el lenguaje epistemológico relativo al ver para expresar diferencias de orden relacional que remiten a una ontología $a^{11}$ diferente.

En esta concepción perspectivista, la apariencia corporal o "cuerpo visible" (Viveiros de Castro 2015: 229) es variable y específica a cada especie, similar a una "ropa" que puede descartarse o cambiarse (véase Chaumeil 1983; Århem 1993; Rivière 1994, entre otros). Por contraste, habría una "esencia antropomorfa espiritual" (Viveiros de Castro 2015: 229) invisible que es común a todos los seres animados y que incide en que sean considerados "gente". Terence Turner (2009) sostiene que Viveiros de Castro sustenta la existencia de dicha "espiritualidad" (Turner 2009: 21) en una lectura errónea de los mitos amazónicos que si bien hablan de un estado original de indiferenciación entre humanos y animales, no dicen que estos últimos se identifiquen a sí mismos como humanos. Extraer de dichas narraciones tal idea responde, según Turner, a un antropocentrismo implícito en la teoría de Viveiros de Castro y no a la evidencia etnográfica. Tampoco la conceptualización del autor brasileño sobre el cuerpo como "ropa" intercambiable y origen de las perspectivas se libra de las críticas (Turner 2009: 30-34). Variados trabajos que recuperan, entre otras, la noción de "engagement" (Ingold 2000: 42), muestran que las perspectivas más que depender de los regímenes corporales estables de cada especie, responden y se construyen en situaciones relacionales específicas. Véase, por ejemplo, en Willerslev (2004), cómo ciertas prácticas miméticas les permiten a los cazadores yukaghirs adoptar una "doble perspectiva" y ser "similares" (2004: 629) a sus presas. Nótese también en Arregui (2019) que el modo en que los pescadores tradicionales ribereños de la Amazonía caracterizan intermitentemente a los delfines rosas como mansos, bravos o amigos depende de ciertas "historias corporales íntimas" (2019: 18) que se inter-

10 Para dar cuenta de esta doble "personalidad" de los animales, Aparecida Vilaça usa, en cambio, el concepto de "sociomorfismo" (1992: 59). Mientras que ella enfatiza la dimensión social de los existentes con doble personalidad, la utilización de "antropomorfismo" por parte de Viveiros de Castro pareciera acentuar la idea de que el anthropos es la "condición original común" a humanos, animales y otros seres (Viveiros de Castro 2015: 229).

11 "Ontología" es usado por primera vez por Viveiros de Castro en las conferencias de 1998. Tal como él mismo posteriormente aclarará, su intención entonces era realizar una crítica al exceso de preocupaciones de orden epistemológico que reducían el conocimiento antropológico al estudio del conocimiento del otro (sus formas de saber, clasificar y organizar el mundo, etc.). Bajo la influencia de Roy Wagner y su tratamiento de los conceptos de "naturaleza" y "cultura", de "dado" y "construido", el término "ontología" permitió al antropólogo brasileño mostrar que la naturaleza (lo "ontológico") podía variar tanto como la cultura (lo "epistemológico"). Su utilización de este concepto para referirse a los universos amerindios intentaba dar cuenta, entonces, de "los objetos de los conceptos de esos otros, para saber de qué está hecho el mundo en que viven" (Viveiros de Castro 2017: 271). 
sectan e influyen mutuamente en razón de dinámicas de la práctica pesquera diaria que no pueden reducirse a premisas cosmológicas dadas de antemano.

La existencia de un substrato anímico o "esencia espiritual" -que en el perspectivismo es visible sólo para aquellos de la misma especie o para seres trans-específicos como los chamanes- nos remite al "animismo" tal como fue desarrollado por el antropólogo francés Philippe Descola a partir de su etnografía entre los achuar de la Amazonía ecuatoriana. Entendido como "modo de identificación" u ontología, el animismo sostiene que diversos seres no-humanos están dotados de las mismas cualidades de "interioridad" 12 que los seres humanos, es decir, ellos también son considerados "persona".

La noción de persona -vía de acceso privilegiada para el estudio de las ontologías- fue crucial en la caracterización del perspectivismo. Según éste, la persona no es un sustantivo sino un pronombre que señala la posición de sujeto; posición que no refiere a la "humanidad como especie" sino a "la humanidad como condición" (Descola 1986: 120). En efecto, Viveiros de Castro (1996: 118) muestra que la posición de persona funciona, en las cosmologías amazónicas, como un "deíctico". Es decir, el ser persona no es allí un atributo exclusivo y esencial de algunas especies sino que ocupar la posición de sujeto con interioridad y, por tanto, tener un punto de vista, depende de cuestiones contextuales y de grado. Tal es así que en el perspectivismo no todas las especies animales gozan del mismo estatus ontológico: el énfasis está puesto en la condición de persona de aquellas que, en su relación con los humanos, poseen un rol simbólico y práctico clave (los grandes predadores, las presas preferidas, etc.) (Viveiros de Castro 2015: 203). El análisis lingüístico agrega que, de hecho, los araweté no tienen términos que remitan a la humanidad o a la animalidad como categorías generales (Viveiros de Castro 1986). Por el contrario, lo que existen son "conceptos monoléxicos" (1992: 64) que pueden aludir a distintos referentes dependiendo del contexto relacional específico.

Estas indicaciones y el valor chamánico otorgado a ciertos animales en las cosmologías amazónicas, así como la existencia de sofisticadas pautas cinegéticas para tratar a las presas, condujo a asociar las ontologías animistas y perspectivistas con un tipo específico de sociedad indígena: las cazadoras-recolectoras. Sin embargo, como indica Viveiros de Castro (2015: 208-209), en el perspectivismo la importancia de la cacería es de orden simbólico y no ecológico, por lo que pueden haber pueblos que, aun siendo horticultores, confieran un peso cosmológico central a la "predación animal" o a la "subjetivación espiritual de los animales". Así, más que remitir a cuestiones derivadas de la actividad económica, estas ontologías ponen de manifiesto la estrecha cercanía y relación de involucramiento con el entorno de los pueblos amazónicos en los que "el animal es el prototipo extra-humano de lo Otro y mantiene relaciones privilegiadas con otras figuras prototípicas de alteridad tales como los afines" (Viveiros de Castro 2015: 209; ver también Descola 1986: 2).

Como mencionamos al inicio, la sociocosmología araweté se funda en la oposición entre humanos y enemigos (bïde y awi). La descripción de la relación que este

12 Con "interioridad" Descola (2005) se refiere tanto a características internas o propiedades asociadas al alma o a la consciencia (reflexividad, afectos, aptitudes para soñar, etc.), como a condiciones físicas (soplo de vida, energía vital, etc.). La "fisicalidad" remite a la forma exterior, que no se circunscribe a la materialidad del cuerpo y abarca también procesos fisiológicos, capacidades perceptivas, temperamento, fluidos corporales, regímenes alimenticios, entre otros. 
pueblo entabla con los pecaríes y otras presas menores (quienes ven a los araweté como enemigos, pero a quienes los araweté no perciben como tales) y con los jaguares (que sí son vistos como enemigos por los araweté) le permitió a Viveiros de Castro ilustrar etnográficamente el juego de perspectivas entre las posiciones de humanos y enemigos durante la cacería (1992: 343). Por otra parte, su análisis del chamanismo y la guerra en esta sociedad también demuestra que tanto el status de chamán como el de guerrero refiere más a perspectivas particulares que a posiciones estabilizadas (1992: 248). Mediante una descripción extensa de los cantos guerreros araweté, Viveiros de Castro (1986: 576-601) postula que la relación entre los guerreros y sus víctimas comienza siendo de alteridad total y termina en la interiorización del punto de vista ajeno: a través de cantos en los que el enemigo es el narrador, el guerrero conoce y asimila la perspectiva de este último. Algo similar ocurre con los cantos chamánicos, que son, a decir del autor, "cámaras de ecos donde siempre se sabe que otro habla" (1986: 604), es decir, cantos que incorporan otras perspectivas. Es la descripción y estudio de estas dinámicas, entre otras (como por ejemplo el ámbito del parentesco y, en especial, el tratamiento de los afines), lo que condujo a Viveiros de Castro a sostener etnográficamente la centralidad de la perspectiva entre los araweté. En su tesis doctoral (1986) muestra que en su relación con los otros (sean estos dioses, enemigos, presas o afines potenciales), los araweté lidian siempre con otros puntos de vista.

En síntesis, la percepción que unos seres tienen de otros, la potencialidad de devenir-otro, el substrato no esencial que permite el trueque de perspectivas y la posibilidad de asumir un punto de vista y ser persona contextualmente son algunos de los pilares etnográficos que dieron pie a las conceptualizaciones de Viveiros de Castro sobre el perspectivismo amerindio. Este ni surgió bajo la forma de una teoría metafísica occidental (ya que su inspiración proviene de la etnografía amazónica) ni emergió de la mera imaginación conceptual de Viveiros de Castro (puesto que se inserta en una historia disciplinar regional particular ${ }^{13}$ ). De hecho, aunque en la obra del precursor del americanismo, Claude Lévi-Strauss, el perspectivismo no aparece explicitado bajo los términos que el antropólogo brasileño utilizará luego, sí encontramos en ella -específicamente, en las Mitológicas (1964, 1967, 1968 y 1971)- alusiones a temas perspectivistas expuestos como una verdadera antropología indígena: cambios de piel y ropas, "multiplicidades sensibles y devenires-animales" (Viveiros de Castro 2009: 19), metamorfosis interespecíficas y matrimonios entre humanos y animales posibles por la "two sided nature" de los seres míticos (Lévi Strauss 1991, citado en Viveiros de Castro 2015: 202, nota 7), entre otros. Además, en La alfarera celosa, se menciona claramente la "reciprocidad de perspectivas" como una característica central de los mitos amerindios (Lévi Strauss 1985: 265 citado en Viveiros de Castro 2015: 202). Todas estas ideas previas sin duda influyeron en la postulación del perspectivismo no solo como una concepción propiamente araweté, sino como una alter-antropología y una metafísica chamánica común a diversos pueblos indígenas amazónicos.

13 Además de la revisión de etnografías amazónicas, el debate con antropólogos melanesistas fue también clave en la formulación del perspectivismo. The invention of culture (1975) de Roy Wagner se volvió el "mediador crucial para la teoría del perspectivismo amerindio" (Viveiros de Castro 2009: 16). The gender of the gift (1988) de Marilyn Strathern es otro interlocutor posible, ya que allí se desarrollan en extensión las particularidades melanesias del intercambio de perspectivas. Véase Goldman (2016: 128-132). 


\section{Del perspectivismo como teoría antropológica al perspectivismo como metafísica amazónica y alter-antropología nativa}

El perspectivismo interespecífico, la ontología multinaturalista y la alteridad caníbal constituyen los pilares de lo que comenzará a conceptualizarse luego como una "metafísica" propiamente amazónica. En efecto, este triángulo conceptual es el que le permitirá a nuestro autor delinear "una de esas filosofias 'de los pueblos exóticos' que Lévi-Strauss contraponía a la "nuestra"" (Viveiros de Castro 2009: 14). En su diálogo con Peter Skafish (2016: 399) aclara que la metafísica, tal como él la concibe, es una actividad propia de todos los seres humanos y, por tanto, que todos tenemos una, pero que la tenemos de modo diferente. Para explicar este punto, retoma La chute du ciel de Davi Kopenawa y Bruce Albert (2010), donde, según nos dice, el chamán yanomami "intenta explicarnos, en nuestro lenguaje (...), sus preocupaciones metafísicas, que son al mismo tiempo preocupaciones políticas" (Viveiros de Castro en Skafish 2016: 401). Los cuestionamientos que Kopenawa hace allí no distan mucho de las preocupaciones de la antropología o la filosofía no indígena: qué es lo humano, qué es lo social, cuál es la diferencia entre humanos y no-humanos, etc. (Viveiros de Castro 2009, 2014). Sin embargo, las respuestas a dichas preguntas sí difieren, en la medida en que cambian los presupuestos ontológicos desde los cuales se resuelven esos interrogantes. Esto conduce a Viveiros de Castro a sostener que el perspectivismo en tanto metafísica chamánica de los pueblos amazónicos no sólo es un posible objeto de estudio de la antropología académica sino que, sobre todo, es una "alter-antropología". Es decir, una antropología del otro que expresa inquietudes metafísicas en sus propios términos y, al hacerlo, contrasta en sus respuestas con algunas tesis filosóficas arraigadas en Occidente.

En los ya citados trabajos, Turner (2009) y Ramos (2012) señalan que tras estas ideas está la voluntad estructuralista de reducir las realidades etnográficas a principios filosóficos generales. Según estos autores, postulados abstractos tales como "pensamiento amerindio" o "metafísica amazónica" uniformizan a los indígenas al focalizar en lo exótico y desconocer los contextos particulares de cada pueblo. Hay quienes incluso van más allá y sostienen que ni siquiera es posible la generalización al interior de un mismo pueblo indígena: lejos de ser transparentes e internamente conmensurables (Vigh y Sausdal 2014: 63), reducibles a "ficciones académicas" que construyen una "alteridad estandarizada" (Bessire y Bond 2014: 443-444), las realidades indígenas son múltiples y heterogéneas (véase Graeber 2015, Cepek 2016). Finalmente, se ha planteado que así como es problemático considerar al perspectivismo como una metafísica presente en toda la Amazonía, también lo es construir contrastivamente una filosofía occidental homogénea y única. Reducidas a "formulaciones típico-ideales" (Turner 2009: 17) tanto las ideas amazónicas como las occidentales pierden riqueza y complejidad (Ramos 2012, Bessire y Bond 2014). Contra este "apartheid ontológico" (Laidlaw 2012: 3), algunos autores proponen no postular a priori un contenido ontológico específico, unívoco y exclusivo de ciertos pueblos, sino analizar las multiplicidades y las pequeñas variaciones internas (Candea 2011).

Adelantándose a este tipo de señalamientos, Viveiros de Castro había sostenido ya en Cambridge en 1998 que distinguir entre las metafísicas indígenas y occidentales es una "elección en el nivel de generalidad" y que su labor intelectual consiste en "abstraer y generalizar un conjunto de ideas sobre sujetos y objetos, cuerpos y almas, humanos y animales para luego esbozar lo que podría llamarse una "ontología virtual" que subyace a estas generalizaciones abstractas" (Viveiros de Castro 2015: 213). 


\section{De equívocos y antropologías en diálogo}

Si el naturalismo occidental sostiene que hay cosas en sí o "entidades auto-idénticas" (Viveiros de Castro 2009: 40) posibles de ser conocidas y representadas parcialmente a través de la objetivación, las metafísicas amazónicas plantean, en cambio, que lo que existe son múltiples puntos de vista que captan "multiplicidades inmediatamente relacionales" (Viveiros de Castro 2009: 40) del estilo sangre/cerveza. En este ejemplo prototípico del perspectivismo se nos dice que el jaguar percibe la sangre de sus presas como cerveza, hecho que pone de manifiesto la cualidad antropomórfica de todas las perspectivas. Tal como indica Viveiros de Castro (2015: 197), dado que el mundo para los pueblos amazónicos no está hecho de esencias sino de perspectivas relativas, el perspectivismo es una teoría nativa de la percepción y no de la representación: lo que varía en estas metafísicas es el mundo que los diversos existentes ven, y no el hecho de ver el mundo a partir de las mismas categorías y valores. En este sentido, el perspectivismo es un multinaturalismo: el mundo amerindio está hecho de puntos de vista que perciben en función de un cuerpo que no difiere de otros por tener una fisiología o anatomía distinta, sino por ser un "haz de afectos y capacidades" particulares (Viveiros de Castro 2009: 40).

En efecto, para la metafísica chamánica amazónica tal como es descripta y analizada por Viveiros de Castro, no existe un mundo único, sino una multiplicidad de mundos y, además, hay múltiples puntos de vista que simultáneamente captan dicha multiplicidad. Como consecuencia, conceptos homónimos pueden remitir, bajo distintas perspectivas, a referentes distintos. De hecho, sin un referente común y anterior a las diversas visiones del mundo, lo único que pueden hacer los múltiples existentes de las sociocosmologías amazónicas es saber, en su relacionarse cotidiano, que las distintas especies no están hablando de lo mismo a pesar de que usan los mismos términos y que estos son, por tanto, "homónimos engañosos" (Viveiros de Castro 2004: 7).

Tal equivocidad no constituye, en la obra de Viveiros de Castro, sólo una referencia al tipo de régimen de comunicación imperante entre los seres del cosmos amazónico, sino que es uno de los datos etnográficos que dará lugar a lo que él denomina "equivocación controlada". Ésta es un "método de descripción antropológica de los mundos indígenas que postulan esas diferencias de mundos" (comunicación personal, traducción nuestra) y permite, según su autor, pensar estrategias de descripción que den mejor cuenta de modos de existencia que difieren en sus bases de los euroamericanos ${ }^{14}$. Diógenes Cariaga (2018: 243) expresa atinadamente que el perspectivismo -al menos en sus formulaciones más tardías, agregaríamos nosotras- no es tanto una ontología amerindia como un modo específico de describir ontologías amerindias.

Emulando la inherente equivocidad de la socialidad amazónica, esta reflexión por parte de Viveiros de Castro y su intento de actualización de la tarea antropológica se basa en entender que, en el encuentro etnográfico, antropólogos y nativos no ne-

14 Un grupo de investigadores que presenció el curso de Viveiros de Castro de 1998, recupera desde hace algunos años este llamado metodológico a "perspectivizar" la antropología tomando algunas de las premisas del perspectivismo amerindio como inspiración para repensar la labor disciplinar. Véase la obra de Holbraad y Pedersen (2017) para un desarrollo pormenorizado de este punto y de la influencia de Viveiros de Castro en el llamado "giro ontológico" en antropología. 
cesariamente hablan de las mismas cosas en los mismos términos. Por eso, traducir supondría dar cuenta de estas diferencias y, sobre todo, permitir que ellas se expresen cabalmente, haciendo visibles las potencialidades de los otros modos de existencia sin opacarlos bajo grandes explicaciones que le son ajenas o reducirlos a versiones más o menos cercanas o lejanas a nuestros propios modos de existir.

La propuesta metodológica de la "equivocación controlada" (así como su par, el "tomar en serio" a aquellos con quienes trabajamos), ha tenido amplia difusión y buena recepción en la antropología en general. Sin embargo, no está exenta de críticas. Vigh y Sausdal (2014), por ejemplo, señalan que la noción de equivocación presupone la existencia de realidades inconmensurables y otorga al antropólogo el privilegio de ser el único capaz de entender el mundo en su multiplicidad y de moverse a través de las diversas perspectivas. Por su parte, Ramos (2012) plantea que el perspectivismo cae en la ventriloquía, puesto que aunque se presenta como una antropología indígena capaz de dialogar con la antropología occidental, en verdad es el antropólogo quien habla en nombre del nativo, lidiando con los equívocos, traduciendo sus mundos y haciéndolos más accesibles. Arregui (2018) nota que en el contexto actual de crisis ecológica global, los mismos actores sociales traducen sus mundos y confluyen miméticamente con otros. Aquí, la equivocación deja de ser un método antropológico o una herramienta conceptual recursiva hecha por y para antropólogos (Arregui 2018: 3) para volver a ser, como en los comienzos del perspectivismo, un régimen de comunicación, un problema con el que los diversos sujetos lidian en sus interacciones de cooperación.

\section{Pensando desde una alter-antropología}

Nuestro recorrido comenzó con los escritos etnográficos de Viveiros de Castro sobre los araweté $(1986,1992)$. Si bien allí ya se trasluce el diálogo que este autor establece con, entre otros, la filosofía deleuziana, ésta cobrará mayor relevancia en textos posteriores, en los que, como explicitamos, se detallan y analizan las características centrales de la cosmología araweté, se las relaciona con las encontradas en otros pueblos amazónicos y se postula, finalmente, una teoría antropológica denominada "perspectivismo" caracterizada como una metafísica chamánica amazónica y una posible alter-antropología. Alcanzado este grado de abstracción, el perspectivismo ya no refiere únicamente a una particularidad sociocosmológica de los pueblos de la Amazonía sino que se vuelve, también, un dispositivo teórico útil para repensar la labor antropológica en general, sus alcances y limitaciones metodológicas y las implicancias políticas del diálogo que, como antropólogos, establecemos con otros en el campo.

Estas son preocupaciones presentes a lo largo de toda la historia de la disciplina. En la reunión anual de la American Anthropological Association del año 2013, por ejemplo, se discutieron las consecuencias teóricas, políticas y metodológicas del "giro ontológico", un giro heterogéneo y amplio en cuyo centro se ubican, entre otras, las obras de Roy Wagner, Marilyn Strathern, Tim Ingold, Philippe Descola y también la producción de Viveiros de Castro y numerosas investigaciones posteriores profundamente influidas por él. En ocasión de este congreso, Tony Crook sostuvo que el interés renovado por las ontologías en la antropología evidenció una correlación directa e incluso un cierto "isomorfismo" entre el objeto etnográfico y 
el método antropológico. Siendo así, según este antropólogo, "toda descripción etnográfica es también una descripción de la antropología que la produce" (Crook 2014). Si traemos ahora sus palabras a colación es porque el recorrido emprendido a través de distintos textos de Viveiros de Castro procuraba mostrar, justamente, cómo etnografía, teoría y un particular compromiso ético y político respecto de qué hace o qué debe hacer la antropología se conjugan en la labor emprendida por este autor. Quisiéramos ahora, para concluir, retomar algunas de las cuestiones que sobrevuelan este texto sobre los distintos sentidos asumidos por el perspectivismo y ponerlos también a ellos en perspectiva.

En primer lugar, debemos mencionar que, en cuanto teoría, el perspectivismo no sólo fue creciendo en abstracción sino también en alcance. Diversas investigaciones analizaron su utilidad y pertinencia en ámbitos etnográficos tales como Asia, Melanesia o las Tierras Altas Sudamericanas (Strathern 1999; Pedersen et al. 2007; Cavalcanti-Schiel 2014, respectivamente). Estas exploraciones, más que validar la propuesta de Viveiros de Castro, han abonado, cada una desde sus particularidades, la idea de que existen otras antropologías que no conceptualizan el cuerpo y el alma, lo individual y lo social, el sujeto y el objeto, el ser y el devenir, del modo usual en Occidente. De hecho, tal como sugiere Cavalcanti-Schiel (2014: 276) en su estudio sobre los Andes, "aunque la incidencia del perspectivismo en los Andes es exigua, los andinos no dejan de ser multinaturalistas a su manera (...) el perspectivismo podría ser visto, en el contexto de un horizonte amerindio, como una forma particular de un multinaturalismo más general".

Esto nos conduce a una segunda cuestión: la constatación de la existencia relativamente extendida de dicho multinaturalismo es la que ha dado lugar a lo que el mismo Viveiros de Castro (comunicación personal) distingue como vertientes principales de la antropología contemporánea, a saber, la preocupada por las ontologías y la multiespecie. Si bien él mismo rehúsa ser ubicado en cualquiera de ellas, lo cierto es que sus trabajos han incidido en ambas. Eduardo Kohn (2015) considera las investigaciones de Viveiros de Castro dentro del "narrow turn", los preliminares de un giro ontológico en antropología que en los años subsiguientes iría ganando en extensión y relevancia. Este giro postula, a grandes rasgos y en consonancia con el multinaturalismo, que no existen diferentes representaciones de un mismo mundo, sino diferentes mundos que deben ser aprehendidos y descriptos antropológicamente como tales. La relación con la antropología multiespecie resulta también clara: si, como postula Viveiros de Castro, hay sociedades para las cuales el anthropos tal como es concebido en Occidente no tiene lugar (puesto que la posibilidad de ser persona, de actuar, desear y de comunicarse está ampliada y distribuida entre los diversos seres), entonces ya no es viable una ciencia antropológica centrada en el hombre como ser superior con capacidades cognitivas y espirituales únicas. Esto abre la posibilidad a investigaciones sobre el giro animal, estudios de ciencia y tecnología, la "antropología de la vida", el posthumanismo, etc., que abordan el ámbito de "la naturaleza" sin reducirla a su relación con los humanos, es decir, de modo no-antropocéntrico (Haraway 2008; Kirksey y Helmreich 2010; Kohn 2013; Pitrou 2014, para citar sólo algunos).

Finalmente, nos resta puntualizar que, como ya indicamos, el perspectivismo más allá de sus diversas acepciones- permite establecer diálogos con otras antropologías en un plano de mayor equidad epistemológica. Aquí radica, tal vez, su mayor potencial. Como proyecto de "descolonización permanente del pensamiento" (Vivei- 
ros de Castro 2009), nos invita a pensar en la existencia de modos de vida distintos a los nuestros, regidos bajo otros modelos de lazo social, con ideas menos sustancialistas de lo que es la persona y el grupo, con concepciones sobre la causalidad y la temporalidad que difieren de aquellas a las que estamos acostumbrados, etc. Independientemente de estar de acuerdo o no con los postulados de base de la antropología de Eduardo Viveiros de Castro, es innegable su potencial para incitarnos a pensar y a actuar. Las formas más simétricas y relacionales que propone, el modo en que las verdades se alternan, yuxtaponen y confrontan unas a otras, la aceptación de la diferencia per se y la confianza en que, de todos modos, es posible el diálogo fructífero, trascienden en algún sentido las modas disciplinares, las particularidades regionales y las diversas corrientes antropológicas. Trascienden, incluso, el ámbito científico. El perspectivismo como metafísica chamánica amazónica y alter-antropología que pone en tensión nuestras propias metafísicas y antropologías, no es, por supuesto, ni la respuesta a todo ni la verdad última. Sin embargo, contrario como es a la homogenización y la estabilización, el perspectivismo nos alienta a indagar en nuestra propia tarea como antropólogos y actualizar todas sus potencialidades, dejándonos siempre un lugar al que escapar de nosotros mismos y de nuestras propias metafísicas.

Agradecimientos. Agradecemos a los evaluadores de la revista por su revisión tan aguda y detallada. También a Eduardo Viveiros de Castro por su lectura atenta a una versión preliminar de este texto. Sus finos comentarios nos permitieron precisar ciertos detalles sobre los fundamentos etnográficos de sus argumentos.

\section{Referencias}

Århem, Kaj. 1993. "Ecosofía makuna”, en La selva humanizada: Ecología alternativa en el trópico húmedo colombiano, François Correa, ed., pp. 109-126. Bogotá: Instituto Colombiano de Antropología.

Arregui, Aníbal G. 2018. "Embodying Equivocations: Ecopolitical Mimicries of Climate Science and Shamanism". Anthropological Theory 20 (3): 330-356. https://doi.org/10.1177/1463499617753335.

-. 2019. "Positional Wildness: Amazonian Ribeirinhos, Pink Dolphins and Interspecies Affections". Ethnos 85 (5): 819-842. https://doi.org/10.1080/00141844.2019.1619606.

Bessire, Lucas y David Bond. 2014. "Ontological Anthropology and the Deferral of Critique". American Ethnologist 41 (3): 440-456. https://doi.org/10.1111/amet.12083.

Candea, Matei. 2011. "Endo/Exo". Common Knowledge 17 (1): 146-150. https://doi.org/10.1215/0961754X-2010-046.

Cariaga, Diógenes E. 2018. “A vida instável dos conceitos: transformação e comparação, uma contribuição americanista - Apresentação ao artigo traduzido de Eduardo Viveiros de Castro". Aceno 5 (10): 241-246. https://periodicoscientificos.ufmt.br/ojs/index.php/aceno/article/view/8603/pdf.

Cavalcanti-Schiel, Ricardo. 2014. "Para além de terras altas e terras baixas: modelos e tipologias na etnologia sul-americana”. Revista de Antropologia 57 (2): 251-290.

Cepek, Michael. 2016. "There Might Be Blood: Oil, Humility, and the Cosmopolitics of a Cofán Petro-Being”. American Ethnologist 43 (4): 623-635.

Chaumeil, Jean-Pierre. 1983. Voir, savoir, pouvoir: le chamanisme chez les Yagua du nord-est péruvien. París: École des Hautes Études en Sciences Sociales. 
Course, Magnus. 2013. “Speaking the Devil's Language: Ontological Challenges to Mapuche Intersubjectivity". Language \& Communication 33 (3): 307-316. https://doi.org/10.1016/j.langcom.2012.10.003.

Crook, Tony. 2014. "Onto-Methodology". Theorizing the Contemporary, Fieldsights, January 13. https://culanth.org/fieldsights/onto-methodology.

Descola, Philippe. 1986. La nature domestique: symbolisme et praxis dans l'écologie des Achuar. París: Maison des Sciences de L'Homme.

—. 2005. Par-delà nature et culture. París: Gallimard.

Goldman, Marcio. 2016. "Marilyn Strathern: Uma antropologia em câmera lenta", en Mais alguma antropologia. Ensaios de geografía do pensamento antropológico, pp. 118-152. Río de Janeiro: Ponteio.

Graeber, David. 2015. "Radical Alterity is Just another Way of Saying 'Reality'. A Reply to Eduardo Viveiros de Castro". Hau: Journal of Ethnographic Theory 5 (2): 1-41.

Gray, Andrew. 1996. The Arakmbut of Amazonian Peru, Vol. I: Mythology, Spirituality and History. Oxford: Berghahn.

Haraway, Donna. 2008. When Species Meet. Minneapolis: University of Minnesota Press.

Holbraad, Martin y Morten Axel Pedersen. 2017. The Ontological Turn. An Anthropological Exposition. Cambridge: Cambridge University Press.

Ingold, Tim. 2000. The Perception of the Environment. Essays on Livelihood, Dwelling and Skill. Londres: Routledge.

Kirksey, S. Eben y Stefan Helmreich. 2010. "The Emergence of Multispecies Ethnography". Cultural Anthropology 25 (4): 545-576. https://doi.org/10.1111/j.1548-1360.2010.01069.x.

Kohn, Eduardo. 2013. How Forest Think. Toward an Anthropology beyond the Human. Berkeley: University of California Press.

2015. "Anthropology of Ontologies". Annual Review of Anthropology 44: 311-327. https://doi.org/10.1146/annurev-anthro-102214-014127.

Kopenawa, Davi y Bruce Albert. 2010. La chute du ciel. Paroles d'un chaman yanomami. París: Plon.

Laidlaw, James. 2012. “Ontologically Challenged”. Anthropology of this Century 4. http://aotcpress.com/articles/ontologically-challenge.

Latour, Bruno. 2009. “Perspectivism: 'Type' or 'Bomb'?” Anthropology Today 25 (2): 1-2. https://doi.org/10.1111/j.1467-8322.2009.00652.x.

Lévi Strauss, Claude. 1964. Le cru et le cruit. París: Plon.

—. 1967. Du Miel aux Cendres. París: Plon.

—. 1968. L'Origine des Manières de Table. París: Plon.

—. 1971. L'Homme Nu. París: Plon.

- 1985. La Potière Jalouse. París: Plon.

—. 1991. Histoire de Linx. París: Plon.

Lima, Tânia Stolze. 1995. A parte do cauim - etnografia Juruna. Tesis de doctorado. PPGAS Museu Nacional, Universidad Federal de Río de Janeiro, Río de Janeiro.

—. 1996. "O dois e seu múltiplo: reflexões sobre o perspectivismo em uma cosmologia tupi". Mana 2 (2): 21-47. https://dx.doi.org/10.1590/S0104-93131996000200002.

—. 2005. Um peixe olhou para mim: o povo Yudjá e a perspectiva. São Paulo: Editora Universidade Estadual Paulista, ISA, NUTI.

Pedersen, Morten Axel, Rebecca Empson y Caroline Humphrey. 2007. "Editorial Introduction: Inner Asian Perspectivisms". Inner Asia 9 (2): 141-152.

https://doi.org/10.1163/146481707793646494. 
Pitrou, Perig. 2014. "La vie, un objet pour l'anthropologie? Options méthodologiques et problèmes épistémologiques”. L'Homme 212 (4): 159-189.

https://doi.org/10.4000/lhomme.23786.

Ramos, Alcida Rita. 2012. "The Politics of Perspectivism”. Annual Review of Anthropology 41: 481-494. https://doi.org/10.1146/annurev-anthro-092611-145950.

Rivière, Peter. 1994. "Wysinwyg in Amazonia". Journal of the Anthropological Society of Oxford 25 (3): 255-262.

Seeger, Anthony, Roberto Da Matta y Eduardo Viveiros de Castro. 1979. “A construção da pessoa nas sociedades indígenas brasileiras”. Boletim do Museu Nacional 32: 2-19.

Skafish, Peter. 2016. "The Metaphysics of Extra Moderns: On the Decolonization of Thought. A Conversation with Viveiros de Castro". Common Knowledge 22 (3): 393-414. https://doi.org/10.1215/0961754X-3622248.

Strathern, Marilyn. 1988. The Gender of the Gift: Problems with Women and Problems with Society in Melanesia. Berkeley: University of California Press.

-. 1999. Property, Substance and Effect. Anthropological Essays on Person and Things. Londres: The Athlone Press.

Turner, Terence. 2009. "The Crisis of Late Structuralism. Perspectivism and Animism: Rethinking Culture, Nature, Spirit, and Bodiliness". Tipiti: Journal of the Society for the Anthropology of Lowland South America 7 (1): 3-42.

Vigh, Henrik E. y David B. Sausdal. 2014. "From Essence Back to Existence: Anthropology beyond the Ontological Turn". Anthropological Theory 14 (1): 49-73.

https://doi.org/10.1177/1463499614524401.

Vilaça, Aparecida. 1992. Comendo como gente: formas do canibalismo wari' (pakaa-nova). Río de Janeiro: Editora da Universidade Federal do Rio de Janeiro.

Viveiros de Castro, Eduardo. 1986. Araweté, os deuses canibais. Río de Janeiro: Jorge Zahar/ Anpocs.

- 1992. From the Enemy's Point of View: Humanity and Divinity in an Amazonian Society. Chicago: University of Chicago Press.

—. 1996. "Os pronomes cosmológicos e o perspectivismo ameríndio". Mana 2 (2): 115-144. https://doi.org/10.1590/S0104-93131996000200005.

-. 1998. "Cosmological Deixis and Amerindian Perspectivism". Journal of the Royal Anthropological Institute 4 (3): 469-488.

-. 2004. "Perspectival Anthropology and the Method of Controlled Equivocation". Tipiti: Journal of the Society for the Anthropology of Lowland South America 2 (1): 3-20.

—. 2009. Métaphysiques cannibales. Lignes d'anthropologie post-structurale. París: Presses Universitaires de France.

-. 2014. "Contra-antropología, contra o estado: uma entrevista com Eduardo Viveiros de Castro", entrevistador: Paulo Bull. Habitus 12 (2): 146-163.

-. 2015 (1998). "Cosmological Perspectivism in Amazonia and Elsewhere (Four Lectures Given in the Department of Social Anthropology, University of Cambridge, FebruaryMarch 1998)", en The Relative Native. Essays on Indigenous Conceptual Worlds, pp.189194. Chicago: Hau Books.

—. 2017. "Metaphysics as Mythophysics. Or, Why I Have Always Been an Anthropologist", en Comparative Metaphysics. Ontology after Anthropology, Pierre Charbonnier, Salmon Gildas y Peter Skafish, eds., pp. 249-271. Londres: Rowan \& Littlefield.

Viveiros de Castro, Eduardo, Carolina Álvarez Ávila y Francisco Pazzarelli. 2019. "Sobre cuatro o cinco cosas imposibles", en Conversar Mundos. Naturalezas, Culturas y Ontologías en la Antropología Contemporánea. Entrevistas a Denise Arnold, Bruno Latour, 
Marcio Goldman, Pedro Pitarch, Eduardo Viveiros de Castro, Francisco Pazzarelli, ed., pp. 107-140. Buenos Aires: Palabra Reversa, Ethnographica.

Wagner, Roy. 1975. The Invention of Culture. Chicago: University of Chicago Press.

Willerslev, Rane. 2004. "Not Animal, Not Not-Animal: Hunting, Imitation and Empathetic Knowledge among the Siberian Yukaghirs". Journal of the Royal Anthropological Institute 10 (3): 629-652. https://doi.org/10.1111/j.1467-9655.2004.00205.x. 
